\title{
AIRBORNE RAMAN LIDAR AND ITS APPLICATIONS FOR ATMOSPHERIC PROCESS STUDIES
}

\author{
Zhien Wang ${ }^{l}$, Perry J. Wechsler ${ }^{l}$, Nick Mahon ${ }^{l}$, Decheng $\mathrm{Wu}^{l}$, Bo Liu ${ }^{l}$, Matthew Burkhart ${ }^{l}$, Brent \\ Glover $^{1}$, William Kuestner ${ }^{1}$, Wayne Welch ${ }^{2}$, and Andrew Thomson ${ }^{2}$ \\ ${ }^{I}$ Department of Atmospheric Science, University of Wyoming, Laramie, Wyoming, 820072, USA, \\ *zwang@uwyo.edu
}

${ }^{2}$ Welch Mechanical Designs, LLC, Maryland, USA

\begin{abstract}
Although ground-base Raman lidars are widely used for atmospheric observations, the capabilities of airborne Raman lidar is not fully explored. Here we presented two recently developed airborne Raman lidar systems for the studies of atmospheric boundary layer process, aerosols, and clouds. The systems are briefly introduced. Observation examples are presented to illustrate the unique observational capabilities of airborne Raman lidar and their applications for atmospheric process studies.
\end{abstract}

\section{INTRODUCTION}

Water vapor and aerosol are the two most important ingredients for the weather and climate system [1]. Aerosols can change energy distributions in the atmosphere and at the surface and the top of atmosphere through both direct and indirect effects. Water vapor and their transportation control the global water cycle. Meanwhile, water vapor is the most important greenhouse gas in the atmosphere. Because the sources and sinks for water vapor and primary aerosols are from the surface, the turbulence mixing and convective vertical transportation in the atmospheric boundary layer (ABL) control airsea interactions and land-air interactions. Therefore, ABL processes and surface inhomogenity significantly influence the spatial distributions of water vapor and aerosols. These present a great challenge in observing and modeling aerosol and water vapor.

The spatial variability of water vapor has impacts on many other important atmospheric processes. Weckwerth discussed the effect of small-scale moisture variability on thunderstorm initiation and showed that the typical radiosonde profile has difficulties to capture the small-scale water vapor variability [2]. One important mesoscale water vapor inhomogeneity is the dry line, which is a subject of increasing interest due to its frequent association with convection initiation and subsequent development of severe weather in the southern Great Plains and other locations [3]. Through entrainment and detrainment, small-scale moisture variability also control cloud evolutions.

Therefore, many studies are designed to better understand the water vapor and aerosol variability in the atmosphere, which presents a high demand on new observation capabilities [4]. The spatial variability of aerosol properties can be observed with a range of different methods from airborne sampling and ground-based lidar measurements to space-borne passive and active measurements. However, the spatial variability of water vapor on small scales is still mainly dependent on airborne in situ observations, but the in situ data are limited at the flight level data, which are hard to interpret sometimes due to strong vertical and horizontal water vapor variability. Airborne DIAL systems have demonstrated to be able to provide accurate water vapor measurements with a vertical resolution $\sim 200-400 \mathrm{~m}$ and a horizontal resolution few hundred meters to few $\mathrm{km} \mathrm{[5].} \mathrm{Similar}$ measurements are demonstrated by a large airborne Raman lidar focusing on profiling tropospheric aerosols and water vapor [6].

To provide required high temporal and spatial resolution aerosol, water vapor and temperature measurements for improving processed-oriented study, we developed two airborne Raman lidars to integrate remote sensing with in situ sampling from a small airborne platform, such as University of Wyoming King Air (UWKA). 
This paper first provides an overview of Wyoming Compact Raman Lidar (WCRL) and Multi-function Airborne Raman Lidar (MARLi) and their capabilities. Then, WCRL observation examples from the King Air Planetary boundary layer Exploratory Experiment (KAPEE), which was conducted in 2010 to test WCRL, are provided to illustrate the airborne Raman lidar measurements capabilities and applications. Finally, a summary is presented.

\section{AIRBORNE RAMAN LIDAR SYSTEMS}

\subsection{WCRL specification}

Aimed at working together with in situ instruments in UWKA, the WCRL used a compact box-style design to integrate laser and transmitting optics, telescope, and receiving optics with a T-shape optical bench (see Fig. 1). The two other units of the WCRL are the laser power supply and the data acquisition and control system. The compact and integrated design not only provides the needed stability to maintain the alignment, but also make it easy to be integrated into different aircraft. The mechanical design of the system is provided by Welch Mechanical Designs, LLC.
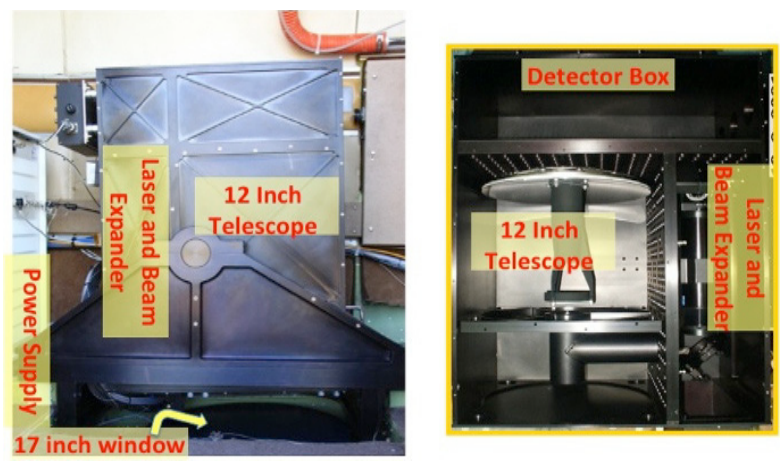

Figure 1. Photos show the installation of WCRL on the UWKA and its internal structure.

WCRL uses a Big Sky CRF 400 laser, which has a compact laser head and stable cavity design. After a $5 \mathrm{X}$ beam expender, the laser beam is transmitted out coaxially. The receiver consists a 12-inch diamond turning telescope providing an excellent thermal stability. The detection system has four channels: $355 \mathrm{~nm}$ perpendicular and parallel depolarization channels, $387 \mathrm{~nm}$ nitrogen Raman channel, and $407 \mathrm{~nm}$ water vapor Raman channel. The system specification is listed in Table 1.
Table 1: Main specification of WCRL

\begin{tabular}{|r|ll|}
\hline \multicolumn{1}{|l|}{ Transmitter } & \\
\hline Laser Wavelength & $355 \mathrm{~nm} \mathrm{Nd:YAG}$ \\
\hline $\begin{array}{r}\text { Pulse Repetition } \\
\text { Frequency }\end{array}$ & $30 \mathrm{~Hz}$ \\
\hline $\begin{array}{r}\text { Pulse width and } \\
\text { Energy }\end{array}$ & $\sim 8 \mathrm{~ns}$ and $50 \mathrm{~mJ}$ \\
\hline Receiver & \\
\hline Telescope & Cassegrain, 12 inch, 0.5-2 mrad \\
\hline Detectors & PMTs & \\
\hline $\begin{array}{r}\text { Data acquisition } \\
\text { system }\end{array}$ & $\begin{array}{l}\text { Analog-only, 200 } \\
\text { channel A/D }\end{array}$ & \\
\hline
\end{tabular}

In order to characterize fine structure of water vapor and aerosols, the system mainly use shortrange strong signals by taking advantage of strong range dependent of lidar signals. Thus, an A/D data acquisition system rather then a photon counting system is used to provide high spatially resolved rdata. For single shot data from UWKA (cruising speed $\sim 100 \mathrm{~m} / \mathrm{s}$ ), the system can provide $0.75 \mathrm{~m}$ vertical, $\sim 3.5 \mathrm{~m}$ horizontal raw data. Different post-averaging can be done according to atmospheric features and applications [7].

\subsection{MARLi specification}

With the low laser power and Raman scattering cross-section, the daytime measurements range of WCRL is limited to $\sim 500 \mathrm{~m}$ below the flight level for the summertime ABL, which is not enough for many ABL process studies. Furthermore, the vertical structure of temperature in the $\mathrm{ABL}$ is critical for ABL process studies. For these reasons and with the NSF MRI support, we are developing MARLi to profile temperature, water vapor, aerosol, and clouds simultaneously.

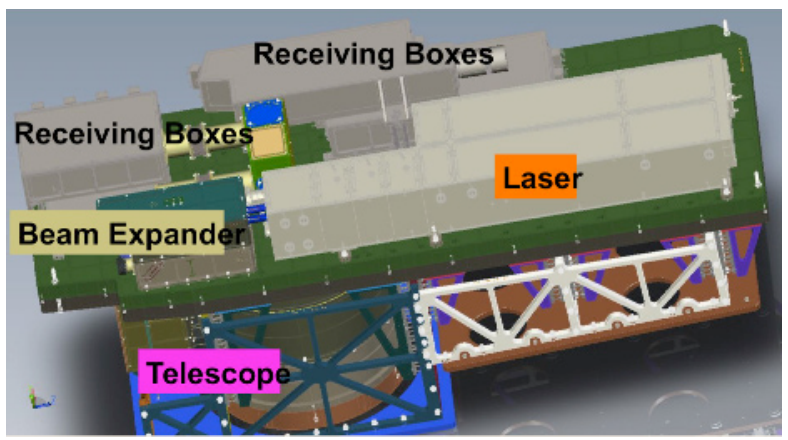

Figure 2. The general layout of MARLi for the installation on UWKA.

To improve the measurement range, MARLi used a powerful laser with $\sim 14 \mathrm{~W}$ power and $30 \mathrm{~Hz}$ at 
$355 \mathrm{~nm}$. Together with a 16 -inch telescope, MARLi is expecting to provide a factor 10 stronger atmospheric Raman signals than those from WCRL. To improve MARLi's capability to profile water vapor over high albedo targets, such as above clouds during daytime, MARLi is capable to transmit $266 \mathrm{~nm}$ laser to provide the solar-blind measurements of water vapor. Such measurement capability will be critical to study cloud-environment interactions. MARLi will have total 13 detection channels to cover needed elastic and Raman channels. Based on the performance of WCRL, MARLi is expected to achieve $0.5 \mathrm{~K}$ and $5 \%$ or better random errors for daytime temperature and water vapor measurements at $90 \mathrm{~m}$ vertical and $1000 \mathrm{~m}$ horizontal resolutions in the summer time ABL when aircraft flies at $2 \mathrm{~km}$ AGL and $100 \mathrm{~m} / \mathrm{s}$.

\section{WCRL OBSERVATION EXAMPLES}

KAPEE was conducted during June 2010 to explore WCRL's capabilities, especially in conjunction with in situ sampling of aerosols and water vapor. During KAPEE, in situ water vapor measurements were available from both a LI-COR $\mathrm{CO}_{2} / \mathrm{H}_{2} \mathrm{O}$ analyzer and a chilled mirror hygrometer (EdgeTech). The chilled mirror hygrometer can provide reliable water vapor measurements with dew/frost point accuracy better than $\pm 0.2^{\circ}$, but with a relatively slow temporal response. On the other hand, LI-COR analyzer can provide $1 \%$ accuracy water vapor measurements at a faster temporal resolution. Other than offering flight level measurements, these two instruments are used to calibrate WCRL water vapor measurements. The calibration of airborne Raman lidar can be done in two easy ways, which are more convenient than the calibration of ground-based Raman lidar systems. First, water vapor profiles within a small cloud free region collected from aircraft spiral descending or ascending can be use to compare with WCRL profile and to exam the overlap differences of between the water vapor and nitrogen Raman channels and to calibrate the system constant [7]. After knowing the short-range overlap difference, we can simply calibrate WCRL water vapor measurements or monitor calibration variations by comparing WCRL near aircraft measurements with in situ measurements. KAPEE results show that good agreements among these measurements can be achieved. Such a comparison is provided in Fig. $3 \mathrm{c}$, where WCRL and LI-COR measurements follow with each other very well and the chilled mirror measurements showed a slow response crossing the dryline.

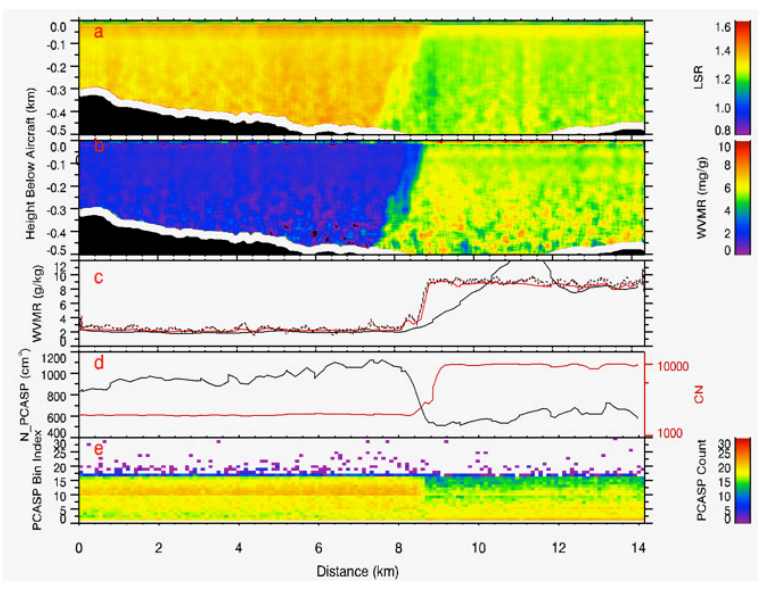

Figure 3. A dryline cross sections observed by WCRL on 22 June 2010: (a) lidar scattering ratio (LSR) and (b) water vapor mixing ratio (WVMR). (c) Comparison of WVMR measured by in situ probes (solid lines, redLi-COR; black-chilled mirror) and by Raman lidar at $40 \mathrm{~m}$ below aircraft (dashed line). (d) CN and PCASP total aerosol concentrations. (e) Aerosol size distributions measured by PCASP. The white lines in (a) and (b) indicate the surface.

The vertical structure of the dryline measured by WCRL is presented in Figs. 3a and 3b. In order to show the fine structure across the dryline, a horizontal running averaging with a less than $50 \mathrm{~m}$ window was done in Fig. 2b. It is clear that the sharp transition from the dry side to the moisture side occurred within $100 \mathrm{~m}$. With WRCL data recorded for each laser shot, different post averaging can be done to better characterize different atmospheric features. For this case, an extended horizontal averaging can be done for either the dry or the moisture side to reduce the random noise in water vapor measurements.

Due to the low power laser of WCRL, its daytime measurement range is limited to $\sim 500 \mathrm{~m}$ below the aircraft. Thus, it took two horizontal legs to reveal the complete dryline structure in the ABL. The spatial distribution of water vapor shows a complex dynamic interaction on the moist side of the dryline, which pushes a $5-\mathrm{km}$ wide water vapor plume into the free troposphere. A deep convection was triggered along this dryline near the time of the observations and developed into a severe storm causing significant damages along the path [8]. 
Figure 3 also shows WCRL aerosol (3a) and in situ PCASP aerosol size distributions and condensation nuclei $(\mathrm{CN})$ number concentrations ( $3 \mathrm{~d}$ and $3 \mathrm{e})$. As expected, aerosol measurements showed similar coherent structures as water vapor across the dryline. The synergy of lidar and in situ aerosol measurements allow for more effective characterizations of aerosol spatial variations.

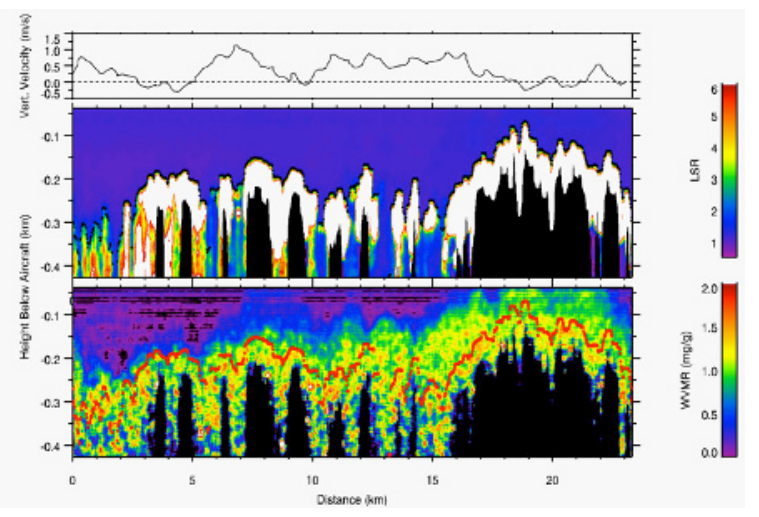

Figure 4. Nighttime measurements of water vapor structure above altocumulus clouds on 25 June 2010. Top: air vertical velocity at the flight level; middle: LSR; bottom: WVMR. The black dots in the LSR plot and the red dots in the WVMR plot are identified cloud top heights.

Another important application of high spatially resolved water vapor measurements is to study cloud and environment interactions, which strongly control cloud evolutions and are poorly understood and simulated in models. Figure 4 provide an example to show altocumulus and environment interactions. Although there is a weak temperature inversion at the cloud top height based on in situ measurements, strong water mixing above cloud top is clearly illustrated with WVMR distributions. Above a few convective cells, the mixing zones are more than $100 \mathrm{~m}$ deep. These measurements offer new data not only to evaluate large eddy simulations, but also to better study related cloud entrainment and detrainment processes.

\section{CONCLUSIONS}

Examples presented here clearly show that airborne Raman lidar is a powerful tool to measure multiple atmospheric parameters simultaneously to support many important atmospheric studies, such as, convective initiation, cloud-environment interactions, atmospheric boundary layer over land and oceans, and mesoscale dynamics. Such studies are fundamental to improving climate simulations and our capability to forecast weather and air quality.

WCRL will be deployed in summer 2015 for the PECAN (Plains Elevated Convection at Night) campaign, which is a large project supported NSF, NOAA, NASA, DOE to advance the understanding of continental, nocturnal, warmseason precipitation. MARLi will be tested in the laboratory in summer 2015 and on NSF/NCAR C130 in fall 2015. Thus more results from these systems will be presented during the meeting.

\section{ACKNOWLEDGEMENT}

This research is supported by NSF under award of AGS-0645644 and AGS-1337599 and University of Wyoming. The UWKA is supported by NSF award ATM 0334908

\section{REFERENCES}

[1] IPCC, 2007: Climate Change 2007: The Physical Science Basis. Solomon, S., et al. (eds.). Cambridge University Press, Cambridge, United Kingdom and New York, NY, USA.

[2] Weckwerth, T.M., 2000: The effect of small-scale moisture variability on thunderstorm initiation. Mon. Wea. Rev., 128, 4017-4030.

[3] Bluestein, H. B., and S. S. Parker, 1993: Modes of isolated, severe convective storm formation along the dryline, Mon. Wea. Rev., 121, 1354-1372

[4]Weckwerth, T. M., and D. B. Parsons, 2006: A review of convection initiation and motivation for IHOP_2002, Mon. Wea. Rev., 134, 5-22.

[5] B Ismail, S., E. V. Browell, R. A. Ferrare, S. A. Kooi, M. B. Clayton, V. G. Brackett, and P. B. Russell, 2000: LASE measurements of aerosol and water vapor profiles during TARFOX, J. Geophys. Res., 105, 99039916

[6] Whiteman, D. N., et al., 2010: Airborne and ground-based measurements using a high-performance Raman lidar, J. Atmos. Ocean. Technol., 27, 17811801 .

[7] Liu B., et al., 2014: Compact airborne Raman lidar for profiling aerosol, water vapor and clouds, Optics express, 22 (17), 20613-20621.

[8] Bergmaier, P. T., et al., 2014: A Dryline in Southeast Wyoming. Part II: Airborne In Situ and Raman Lidar Observations, Mon. Wea. Rev., 142, 2961-2977. 